\title{
Three-Dimensional Echocardiography: Rational Mode of Component Images for Left Ventricular Volume Quantitation
}

\author{
Uwe Nixdorff Isa Feddersen Jens-Uwe Voigt Frank A. Flachskampf \\ 2nd Medical Clinic, University of Erlangen-Nuremberg, Erlangen, Germany
}

\section{Key Words}

Three-dimensional echocardiography $\cdot$ Left ventricular volumetry $\cdot$ Left ventricular function • Left ventricular aneurysm

\begin{abstract}
Three-dimensional echocardiography (3DE) improves the accuracy of left ventricle (LV) volumetry compared with the two-dimensional echocardiography (2DE) approach because geometric assumptions in the algorithms may be eliminated. The relationship between accuracy of mode (short- versus long-axis planimetry) and the number of component images versus time required for analysis remains to be determined. Sixteen latex models simulating heterogeneously distorted (aneurysmatic) human LVs (56-303 ml; mean $182 \pm 82 \mathrm{ml}$ ) were scanned from an 'apical' position (simultaneous 2DE and $3 \mathrm{DE})$. For 3DE volumetry, the slice thickness was varied for the short (C-scan) and long axes (B-scan) in 5-mm steps between 1 and $25 \mathrm{~mm}$. The mean differences (trueechocardiographic volumes) were $16.5 \pm 44.3 \mathrm{ml}$ in the 2DE approach (95\% confidence intervals -27.8 to +60.8$)$ and $0.6 \pm 4.0 \mathrm{ml}$ (short axis; 95\% confidence intervals -3.4 to +4.6 ) as well as $2.1 \pm 9.9 \mathrm{ml}$ (long axis; $95 \%$ confidence intervals -7.8 to +12.0 ) in the $3 \mathrm{DE}$ approach (in both cases, the slice thickness was $1 \mathrm{~mm}$ ). Above a slice
\end{abstract}

thickness of $15 \mathrm{~mm}$, the $95 \%$ confidence intervals increased steeply; in the short versus long axes, these were -6.5 to +8.5 versus -7.0 to +10.6 at $15 \mathrm{~mm}$ and -10.1 to +15.7 versus -11.3 to +10.9 at $20 \mathrm{~mm}$. The intra-observer variance differed significantly $(p<0.001)$ only above $15 \mathrm{~mm}$ (short axis). Time required for analysis derived by measuring short-axis slice thicknesses of 1, 15, and $25 \mathrm{~mm}$ was $58 \pm 16,7 \pm 2$ and $3 \pm 1 \mathrm{~min}$, respectively. The most rational component image analysis for $3 \mathrm{DE}$ volumetry in the in vitro model uses short-axis slices with a thickness of $15 \mathrm{~mm}$.

Copyright $(2005$ S. Karger AG, Basel

\section{Introduction}

Complex left ventricle (LV) geometric alterations during the postmyocardial infarction period must be diagnosed, because such information is important for risk and prognostic assessment, patient behavior recommendations and may also influence drug therapy as well as help determine the best time for cardiac surgery as LV aneurysmectomy. Several studies have shown the improved accuracy of LV volumetry by three-dimensional echocardiography (3DE) [1-7] compared to the two-dimensional echocardiography (2DE) approach $[2,3,6]$.

\section{KARGER}

Fax +4161306 1234 E-Mail karger@karger.ch www.karger.com

\section{(C) 2005 S. Karger AG, Basel}

0008-6312/05/1042-0076\$22.00/0

Accessible online at:

www.karger.com/crd
Uwe Nixdorff, MD

Friedrich-Alexander University, Erlangen-Nuremberg, 2nd Medical Clinic

Ulmenweg 18, DE-91054 Erlangen (Germany)

Tel. +4991318535311, Fax +4991318535313

E-Mail uwe.nixdorff@rzmail.uni-erlangen.de 
Fig. 1. Examples of different-sized ventricular latex models with geometric ('aneurysmatic') distortions (No. 6, 7, 8 and 13) including one with 'experimental aneurysmectomy’ (No. 16).

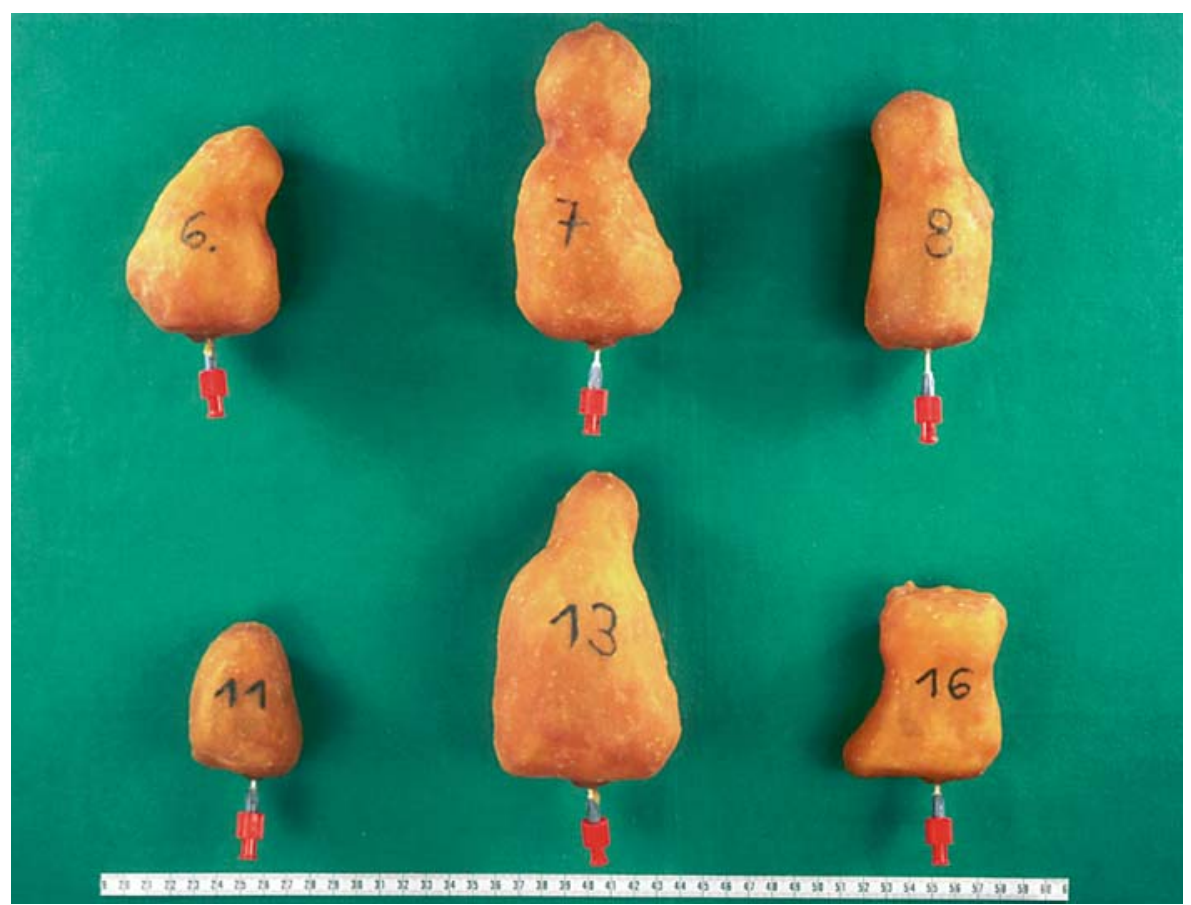

The main drawback of the 3DE approach is the excessive time required for LV volumetry [5]. This is mainly due to manual tracing of endocardial borders of several slices which has also not been eliminated by real-time 3DE. Our in vitro study was directed at establishing the rational procedure to balance out the number of LV slices to be traced and the accuracy of LV volumetry by 3DE.

\section{Methods}

Sixteen latex models simulating distorted human LVs were made. The volumes used were within the broad spectrum of human anatomy and pathology [8] (56-303 ml; mean $182 \pm 82 \mathrm{ml}$ ) simulating mild and severe degrees of aneurysmatic distortions. In some models, aneurysmectomy was simulated by excising these distortions. Examples are shown in figure 1. The ventricles were modelled using air-drying argillaceous earth (efoplast ${ }^{\circledR}$; Faber, Neumark, Germany). The ventricular models were lacquered. The hardening plaster was spread sevenfold by a latex mass (plasty-late ${ }^{\circledR}$; BastelSystem, Neuwied, Germany). After drying, the argillaceous earth

Fig. 2. Examples of two aneurysmatic ventricular models shown by the TomTec system. a A reconstructed short-axis slice (right) from the 3DE data set (left). $\mathbf{b}$ The manual contouring of a shortaxis slice (right) while the already contoured apical slices are implemented in the 3DE data set (left).

Three-Dimensional Echocardiography
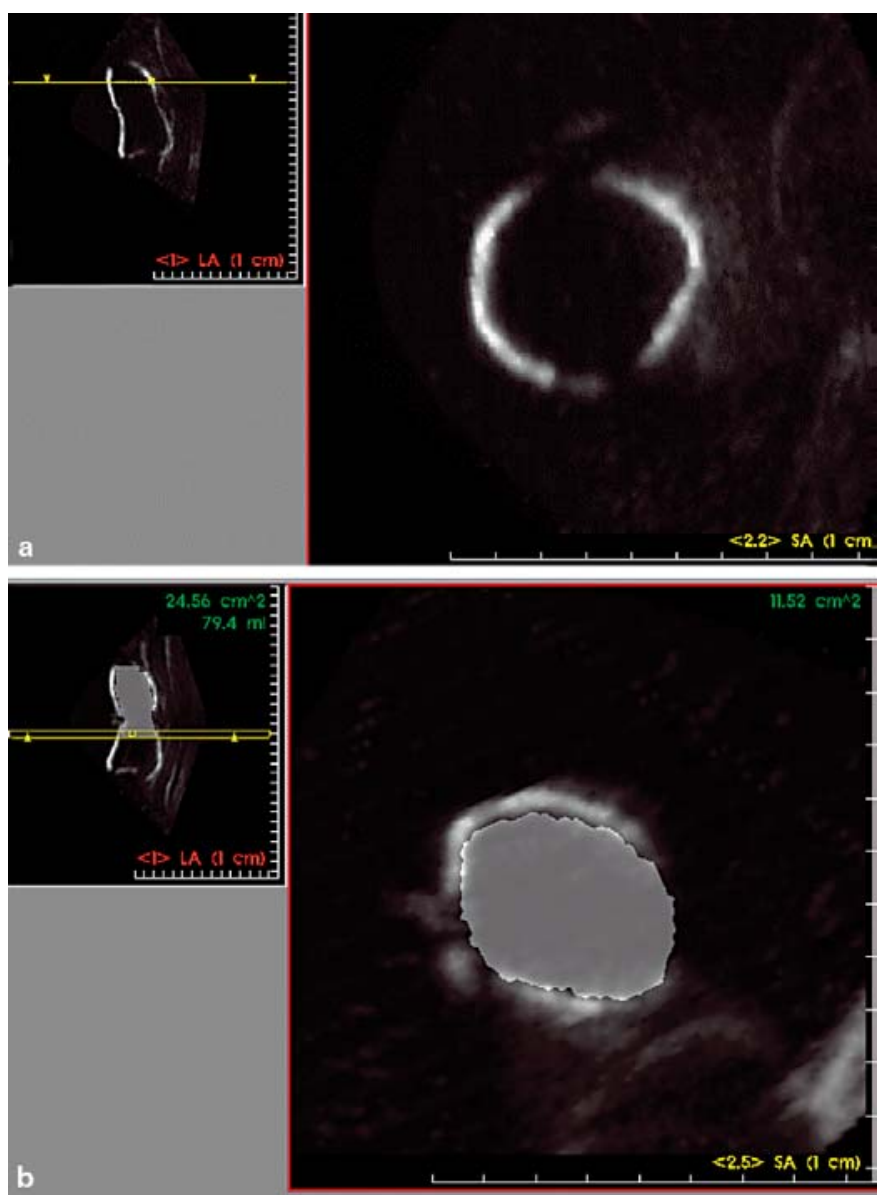

Cardiology 2005;104:76-82 
was broken up and removed through the open base of the latex model. Subsequently, the latex models were closed. The bases were cannulated. True volumes were measured by filling the models with water and measuring the contents subsequently by means of a metric cylindrical cup.

The water-filled latex models were placed in a water tank (temperature $20^{\circ} \mathrm{C}$ ) and a mechanical $3.25-\mathrm{MHz}$ probe was placed at $3 \mathrm{~cm}$ distance from the apex of the model. The probe was covered by a polyacrylic sheet (Barrier ${ }^{\circledR} ;$ Johnson \& Johnson, Warren, USA) usually used for intra-operative scanning to protect it from the water. Echocardiographic images were acquired by a mechanical sector scanner (CFM 800 ${ }^{\circledR}$; GE/Vingmed Sound, Horten, Norway). Grey-scale image settings were adjusted individually. To obtain 3DE images, the sector probe was placed in a rotation device (TomTec-Echoscan ${ }^{\circledR}$; TomTech, Munich, Germany). The 2DE images were digitized by the echo machine and acquired at $2^{\circ}$ angle increments for $180^{\circ}$ rotation. The three-dimensional data set was converted (radial structure of images to cubic pixel = voxel structure) as well as reconstructed by Echoscan. Simultaneously to the acquisition of the three-dimensional data set, 2DE image loops were digitized by the Vingmed machine.

The disc summation method according to the recommendations of the American Society of Echocardiography was applied [9]. In 3DE, the LV volume (V) was divided into n slices (S) (short-axis and long-axis mode, respectively) with a defined height (h). The slice area was obtained (dA) by contouring the endocardial border of the LV in each of these slices manually (fig. 2). The volume of the slices is accordingly:

$$
\mathrm{V}_{\mathrm{S}}=\mathrm{A}_{\mathrm{S}} \times \mathrm{h}_{\mathrm{S}}
$$

The volume of the entire LV is obtained by summarizing all slice volumes:

$$
\mathrm{V}_{\mathrm{LV}}=\sum_{\mathrm{i}}^{\mathrm{n}} \mathrm{V}_{\mathrm{S}}
$$

In 2DE, the standard software (EchoPac ${ }^{\circledR}$ on MacIntosh ${ }^{\circledR}$; GE/ Vingmed Sound) calculated the LV volume by using the biplane disc summation method, which is similar to the method mentioned above. The LV volume in each slice is now determined by 2 perpendicular diameters $(\mathrm{d} 1 / \mathrm{d} 2)$ assuming elliptic rather than circular slices, as the LV is contoured in the 2-and 4-chamber view. In 2DE, summarized volumes of all slices result in the ventricular volume:

$$
\mathrm{V}_{\mathrm{LV}}=\pi / 4 \times \sum_{\mathrm{i}}^{\mathrm{n}}=1 \mathrm{~d} 1 \times \mathrm{d} 2 \times \mathrm{h}_{\mathrm{S}}
$$

We varied the slice thicknesses of the $3 \mathrm{DE}$ volume analyses: 1 , $5,10,15,20$ and $25 \mathrm{~mm}$. The required time for tracing and calculating volumes was noted for each slice thickness in 3DE and 2DE analyses, respectively. To obtain the intra-observer variance, all volume analyses were done three times on 3 different days. To obtain the interobserver variance, the $3 \mathrm{DE}$ volume analysis with $5 \mathrm{~mm}$ slice thickness and 2DE were performed by a second observer.

True volumes and measured volumes (2DE and 3DE volume analyses) were statistically compared as suggested by Bland and Altman [10]. The mean difference between the true and the measured volumes was noted as the bias. The limits of agreement (mean values \pm twofold standard deviation) are equivalent to the $95 \%$ confidence interval. Deviations of differences from zero (under- or overestimation by $2 \mathrm{DE}$ and $3 \mathrm{DE}$ ) were determined by the Student $t$ test. The correlation between true and measured volumes was analysed by linear regression. The inter- and intra-observer variances were analysed by the two-sided t test.

\section{Results}

All latex models had an excellent echogenicity. Due to different LV volume sizes and differing slice thicknesses, the number of slices per model ranged between 3 and 96 . The required time for analyses differed from 1 to $75 \mathrm{~min}$ (25-1 mm slice thickness) in the short-axis mode and from 0.5 to $42 \mathrm{~min}$ (25-1 $\mathrm{mm}$ slice thickness) in the longaxis mode.

The agreement analyses using the short-axis mode are shown for all slice thicknesses in figure 3 . With increasing slice thicknesses, the limits of agreement increase. Between $15 \mathrm{~mm}$ and $20 \mathrm{~mm}$ slice thickness, a stepwise increase is documented in the short $(95 \%$ confidence interval -6.5 to +8.5 vs. -10.1 to +15.7$)$ and the long axis $(95 \%$ confidence interval -7.0 to +10.6 vs. -11.3 to +10.9 ) . Since these differences are relatively small compared to the LV volume, the regression analyses were excellent for all slice thicknesses (fig. 4).

In $2 \mathrm{DE}$, the limits of agreement were -27.8 to $+60.8 \mathrm{ml}$, with an increasing variability for increasing volumes (fig. 5) in contrast to the three-dimensional approach. The correlation coefficient $(r=0.98)$ is not significantly lower compared to that for the three-dimensional approach $(r=0.99)$. Further, the volume underestimation (difference of true and echocardiographic volume: $16.5 \pm 44.3 \mathrm{ml}$ ) exceeds that of 3DE (fig. 5 compared with fig. 3 ).

Comparing the intra-observer variances of the different slice thicknesses, a significant increase is documented above $15 \mathrm{~mm}$ :

$\begin{array}{rll}1 \mathrm{~mm} & \text { short axis: } 1.8 \text {; n.s. } & \text { long axis: } 14.7 \text {; n.s. } \\ 5 \mathrm{~mm} & \text { short axis: } 2.3 \text {; n.s. } & \text { long axis: } 16.3 \text {;.s. } \\ 10 \mathrm{~mm} & \text { short axis: } 5.0 \text {;.s. } & \text { long axis: } 11.6 \text {; n.s. } \\ 15 \mathrm{~mm} & \text { short axis: } 3.1 \text {; n.s. } & \text { long axis: } 15.1 \text { n.s. } \\ 20 \mathrm{~mm} & \text { short axis: } 21.9 ; \mathrm{p}<0.001 & \text { long axis: } 21.4 ; \text { n.s. } \\ 25 \mathrm{~mm} & \text { short axis: } 38.1 ; \mathrm{p}<0.001 & \text { long axis: } 52.3 ; \mathrm{p}<0.001\end{array}$

Comparing variances for the short axis with the long axis, a significantly lower variability for the short axis is seen at slice thicknesses below $20 \mathrm{~mm}: 1,5,15 \mathrm{~mm}(\mathrm{p}<$ $0.001) ; 10 \mathrm{~mm}(\mathrm{p}<0.002)$, and 20 as well as $25 \mathrm{~mm}$ (n.s.). The mean differences of 3 volume measurements in each of the models by different slice thicknesses were low in the short axes below $20 \mathrm{~mm}$ thickness in contrast to higher values above that and in all long-axis slices (fig. 6). 
Fig. 3. Agreement analyses of determined model volumes at the different short-axis slice thicknesses [1-25 mm: 1-mm slices (a), 5-mm slices (b), 10-mm slices (c), 15-mm slices (d), 20-mm slices (e), 25-mm slices (f)]. Plotting of differences of true volume and 3DE volumes (y-axis) against true volume (x-axis). Continuous line represents the mean difference of true and 2DE volume (degree of under- or overestimation), dotted line represents limits of agreement ( twofold standard deviation $=95 \%$ confidence interval).
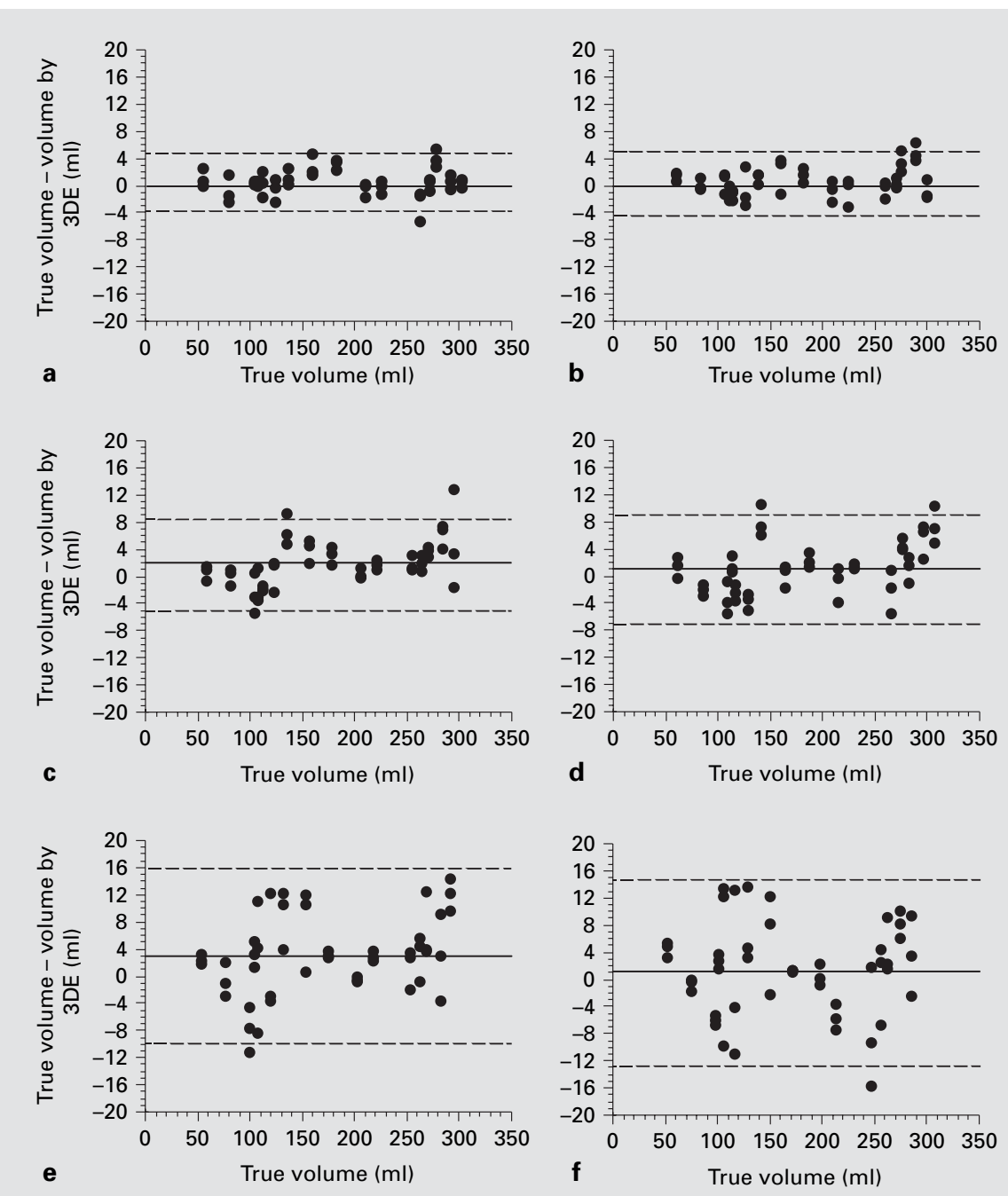

The interobserver variability (5-mm short-axis slice) for the two-dimensional approach was $\mathrm{p}=0.063$ and for the three-dimensional approach $p=0.25$. This indicated a higher variability for $2 \mathrm{DE}$ as a tendency, although this did not reach statistical significance.

\section{Discussion}

Our study proves an excellent agreement and correlation between volumes determined by $3 \mathrm{DE}$ and the true volumes of ventricular models simulating deformed postmyocardial infarction geometry (LV remodelling, aneurysms or after aneurysmectomy). This is due to the excellent registration of geometrical regional alterations, which are of major concern in two-dimensional algorithms. Fur- thermore, our study suggests an optimal slice thickness of $15 \mathrm{~mm}$ traced in the short-axis mode to determine the LV volume in $3 \mathrm{DE}$.

The superiority of three-dimensional images compared to the two-dimensional approach has been reported in other studies $[1-4,6,7]$ compared with the two-dimensional approach $[2,3,6]$, including one with deformed LV [1]. Most of the former studies used transoesophageal data acquisition for LV volumetry [11, 12], but, looking ahead, the future of the method will be associated with the transthoracic approach.

Linear regression analysis is inadequate for determining whether two different methods agree [10], since under- or overestimation are not assessed. However, agreement must be confirmed by statistical analysis, as it is essentially important for volumetry. In our study, both 
Fig. 4. Regression analyses of determined model volumes at different short-axis slice thicknesses [1-25 mm: 1-mm slices (a), 5-mm slices (b), 10-mm slices (c), 15-mm slices (d), 20-mm slices (e), 25-mm slices (f)]. Plotting of $3 \mathrm{DE}$ volumes (y-axis) against true volume (x-axis). Interrupted line represents linear regression.

Fig. 5. a Agreement analysis of $2 \mathrm{DE}$ with plotting of differences of true volume and $2 \mathrm{DE}$ volumes (y-axis) against true volume (x-axis). Continuous line represents the mean difference of true and 2DE volumes (underestimation by 2DE), interrupted line represents limits of agreement (twofold standard deviation $=95 \%$ confidence interval). b Regression analysis of 2DE with plotting of 2DE volumes (y-axis) against true volume (x-axis). Dotted line represents linear regression.
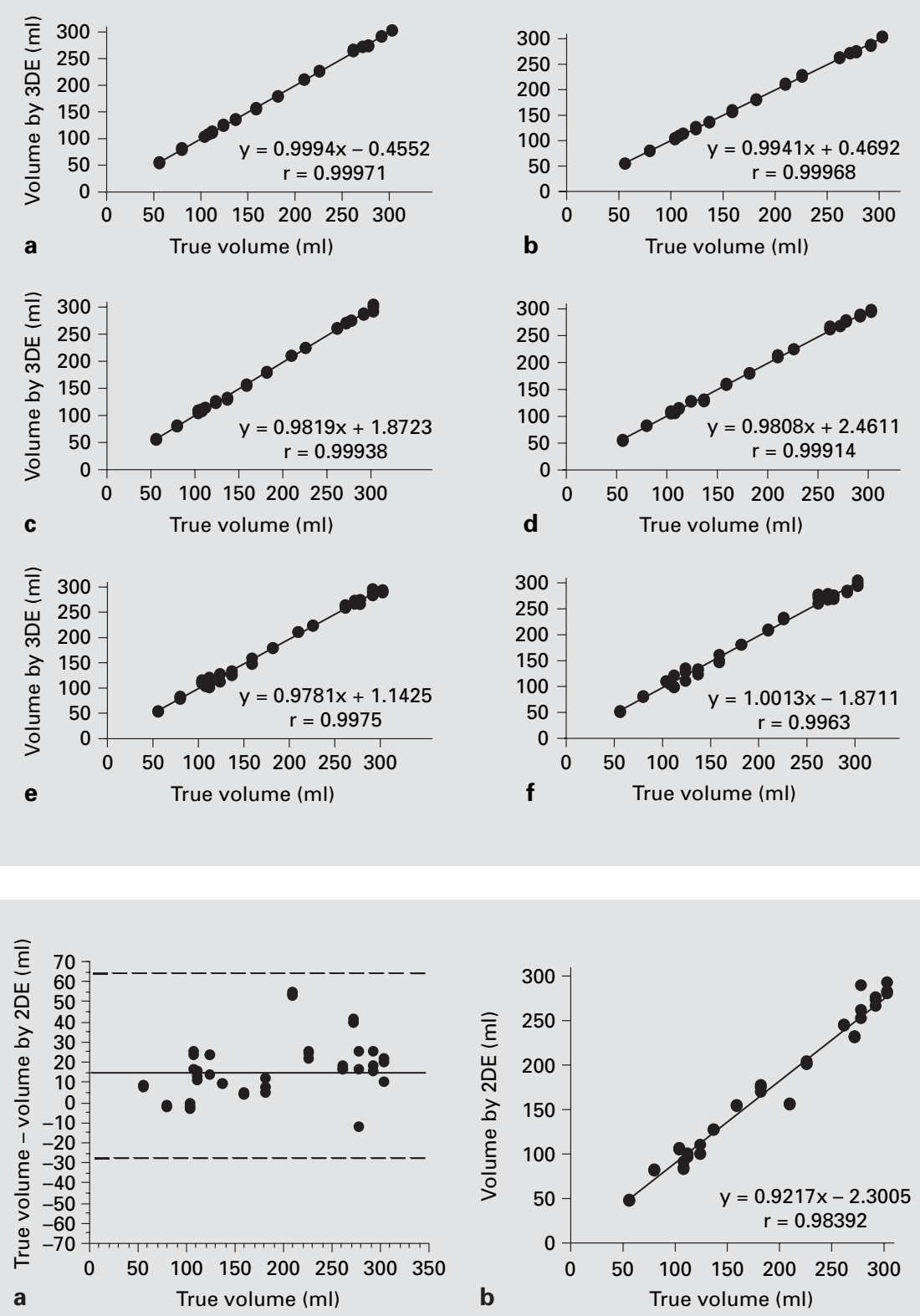

2DE and 3DE demonstrated an excellent correlation with the phantom volume, but the limits of agreement were 6 times narrower with 3DE than with 2DE.

Schröder et al. [13] have reconstructed the volume of 30 water-filled balloons ( $40-200 \mathrm{ml}$, including 15 distorted shaped models) by 2DE and 3DE using the polyhedral surface reconstruction algorithm. 2DE and 3DE had an excellent correlation ( $r=0.97$ vs. $r=0.99)$, but the standard error of estimation was twice larger with 2DE. De- spite the distorted shapes of aneurysmatic LVs, the threedimensional system can accurately reconstruct LV volumes and function in vivo without geometrical assumptions and do not require standardised two-dimensional planes [14]. The achievement of these standardised two-dimensional planes depends on the exact positioning of the apical view, which requires technical skill. Hence, the results obtained with $2 \mathrm{DE}$ volumetry are not up to the mark in about $50 \%$ of the cases [15]. This is in contrast 


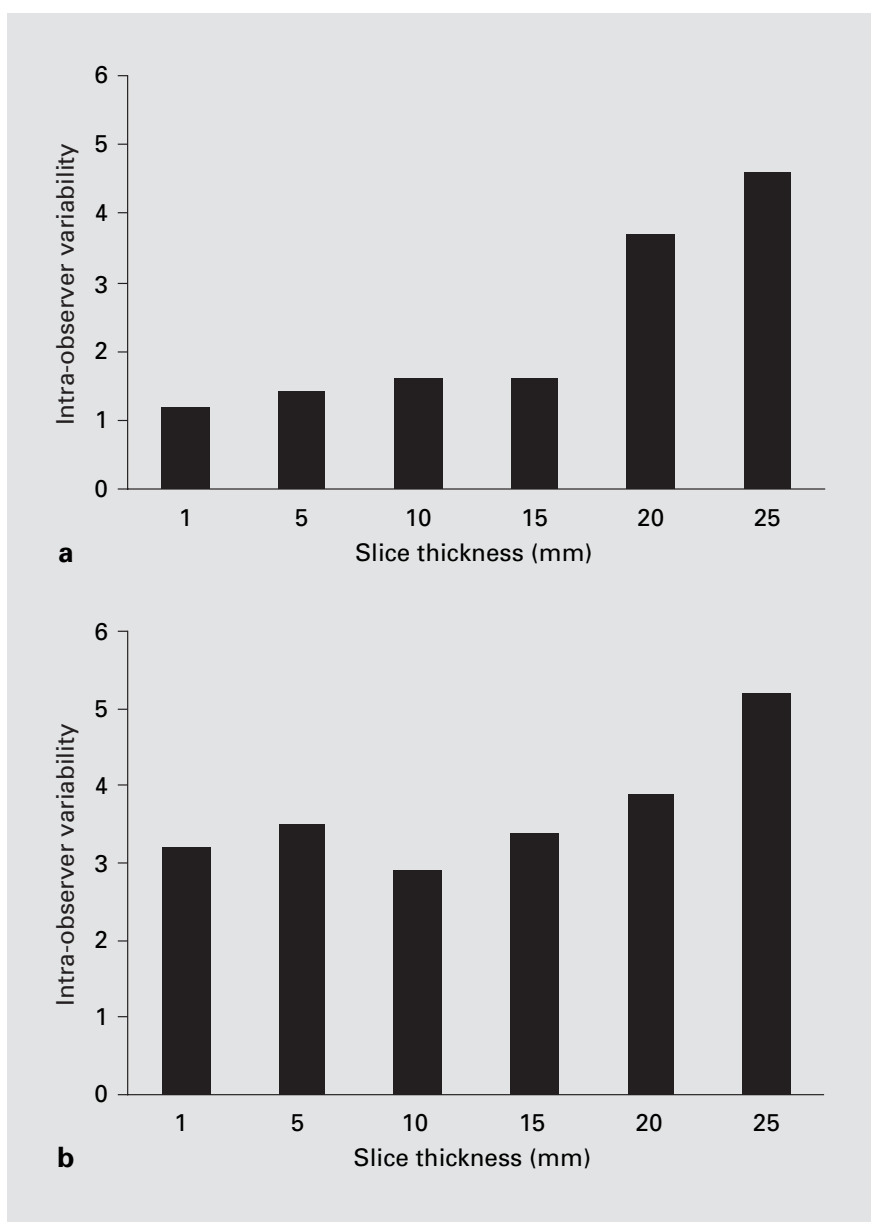

Fig. 6. Intra-observer variability given by mean differences of 3DE volume measurements in each of 16 ventricular models at different slice thicknesses (1-25 mm) in short axes (a) and long axes (b).

with 3DE, where the position of the constructed LV short axes is more objective and reproducible. The only remaining variable is the definition of the longitudinal axis. In clinical studies, the intra- and interobserver variability may be reduced almost twofold by $3 \mathrm{DE}$ [16-18], although it is less effective than in the in vitro setting demonstrated by our data. Furthermore, in our study, 2DE was limited by a progressive underestimation of LV volumes with increasing volume sizes. This was also reported by Sapin et al. [18], who analysed 35 unselected patients with 3DE, 2DE and cineventriculography. In this study, there have been excellent correlations for cineventriculography compared with $3 \mathrm{DE}$ (end-diastolic volume $\mathrm{r}=0.97$ and endsystolic volume $r=0.98$ ) and to a lesser degree for $2 \mathrm{DE}$ (end-diastolic volume $r=0.85$, end-systolic volume $r=$ 0.91). The limits of agreement were about twofold larger in 2DE. The bias in 2DE increased with the size of ventricles. This is especially important for diagnostic accuracy in terms of remodeling postmyocardial infarction.

It is a widely accepted fact that $3 \mathrm{DE}$ takes up too much time [18]. Automated slice contouring is still insufficiently linked with echogenicity, although semi-automated border detection algorithms are encouraging. However, endocardial profiles must be examined for accuracy and manually adjusted in most cases [19]. Thus, one possibility to reduce time requirements is to decrease the number of traced slices. Our study indicates that a slice thickness of $15 \mathrm{~mm}$ (6 \pm 2 slices) may be optimal, since intra-observer variability and agreement analysis did not differ significantly at slice thicknesses $\leq 15 \mathrm{~mm}$. The time required for analysis can be reduced from $58 \pm 16 \mathrm{~min}$ (1-mm slices) to $6 \pm 2 \mathrm{~min}$ (15-mm slices), i.e. approximately by a factor of 10 . Clinically, the time will have to be doubled since the end-diastolic and end-systolic volumes for calculating ejection fraction must be measured. Data acquisition and reconstruction need an additional $3-10 \mathrm{~min}[17,18]$. Our study agrees with a former in vitro study. Siu et al. [20] have suggested 8-12 images (using the line of intersection method). The phantom volumes (14-85 ml) were smaller compared to our phantoms. Nosir et al. [21] also suggested a slice thickness of $15 \mathrm{~mm}$ in an in vivo study. Twenty-five patients (11 with ischaemic heart disease, 5 with dilated cardiomyopathy, 8 during chemotherapy and 1 healthy volunteer) underwent 3DE (disc summation method) and radionuclide angiography. 3DE had shown an excellent correlation with radionuclide angiography $(\mathrm{r}=0.99)$ at $3 \mathrm{~mm}$ slice thickness. Increasing the slice thickness in steps of $3 \mathrm{~mm}$, the standard deviation of the mean difference for $\mathrm{LV}$ volume and LV ejection fraction showed a stepwise increase especially at $>15 \mathrm{~mm}$ thickness.

Nevertheless, $15 \mathrm{~mm}$ slice thickness should not be suggested in clinical routine without critical approval. In in vitro series, potential data acquisition limitations due to ECG and respiratory triggering are not considered. For patients with poor echogenicity or/and with multiple deformed LVs, the number of slices may have to be higher to achieve exact LV volumetry. This was also confirmed by a clinical study by Nosir et al. [22]. They used a 3-mm slice thickness in an in vivo study. They concluded that 3DE on the basis of $3 \mathrm{~mm}$ slice thickness (short-axis mode) provides better correlations and closer limits of agreement than radionuclide angiography for the calculation of LV ejection fraction, particularly in patients with segmental wall motion abnormalities and global hypokinesis. 
The possibility to reconstruct and measure $\mathrm{LV}$ volume in a long-axis mode (paraplane mode or B-mode) cannot be suggested on the basis of our study data. The limits of agreement and intra-observer variability were significantly higher compared to the short-axis mode. In other in vitro studies using balloon models without geometric distortions, short-axis measurements were similarly variable compared with long axes measured as angular sectors
[23]. Volume underestimation - well-known from conventional 2DE [8] - is reported in other in vitro studies with [24] and without geometric distortions [23] but has not been confirmed by our data. However, our measurements were not affected by lateral resolution problems within the short axes assumed to cause this limitation [23, 24].

\section{References}

1 Buck T, Schön F, Baumgart D: Tomographic left ventricular volume determination in the presence of aneurysm by three-dimensional echocardiographic imaging. 1. Asymmetric heart models. J Am Soc Echocardiogr 1996;9: 488-500.

2 Gopal A, King D, Keller A, Rigling R: Superiority of three-dimensional echocardiography in human subjects for ventricular volume computation compared to two-dimensional apical biplane summation of disc method. Circulation 1992;86:I270-I276.

3 Gopal A, Keller AM, Rigling R, King DL Jr, King DL: Left ventricular volume and endocardial surface area by three-dimensional echocardiography: Comparison with two-dimensional echocardiography and nuclear magnetic resonance imaging in normal subjects. J Am Coll Cardiol 1993;22:258-270.

4 Mueller S, Bartel T, Baumann G, Erbel R: Preliminary Report: Evaluation of three-dimensional echocardiographic volumetry by simultaneous thermal dilution in coronary heart disease. Cardiology 1996;87:552-559.

5 Pearlman AS: Measurement of left ventricular volume by three-dimensional echocardiography present promise and potential problems. J Am Coll Cardiol 1993;22:1538-1540.

6 Sapin PM, Schröder KD, Smith MD, De Maria AN, King DL: Three-dimensional echocardiographic measurement of left ventricular volume in vitro: Comparison with two-dimensional echocardiography and cineventriculography. J Am Coll Cardiol 1993;22:15301537.

7 Siu SC, Levine RA, Rivera JM: Three-dimensional echocardiography improves noninvasive assessment of left ventricular volume and performance. Am Heart J 1995;130:812-822.

8 Nixdorff U, Erbel R, Pop T, et al: Long-term follow-up of global and regional left ventricular function by two-dimensional echocardiography after thrombolytic therapy in acute myocardial infarction. Int J Cardiol 1993;41:3147.
9 Schiller NB, Shah PM, Crawford M, et al: Recommendations for quantitation of the left ventricle by two-dimensional echocardiography. American Society of Echocardiography Committee on Standards, Subcommittee on Quantitation of Two-dimensional Echocardiograms. J Am Soc Echocardiogr 1989;2:358-367.

10 Bland JM, Altman DG: Statistical methods for assessing agreement between two methods of clinical measurement. Lancet 1986;i:307310.

11 Krebs W, Klues HG, Steinart S, et al: Left ventricular volume calculations using a multiplanar transoesophageal echoprobe; in vitro validation and comparison with biplane angiography. Eur Heart J 1996;17:1279_ 1288.

12 Kurado T, Kinter TM, Seward JB, Yanagi H, Greenleaf JF: Accuracy of three-dimensional volume measurement using biplane transesophageal echocardiographic probe: In vitro experiment. J Am Soc Echocardiogr 1991;4: 475-484.

13 Schröder KM, Sapin PM, King DL, Smith MD, DeMaria AN: Three-dimensional echocardiographic volume computation: In vitro comparison to standard two-dimensional echocardiography. J Am Soc Echocardiogr 1993;6:467-475

14 Kuhl HP, Franke A, Janssens U, et al: Threedimensional echocardiographic determination of left ventricular volumes and function by multiplane transesophageal transducer: In vitro validation and in vivo comparison with angiography and thermodilution. J Am Soc Echocardiogr 1998;11:1113-1124.

15 King DL, Harrison MR, King DL Jr, et al: U1trasound beam orientation during standard two-dimensional imaging: Assessment by three-dimensional echocardiography. J Am Soc Echocardiogr 1992;5:576-586.

16 Aakhus S, Maehle U, Bjoernstad K: A new method for echocardiographic computerized three-dimensional reconstruction of left ventricular endocardial surface: In vitro accuracy and clinical repeatability of volumes. J Am Soc Echocardiogr 1994; 7:571-581.
17 Kupferwasser I, Mohr-Kahaly S, Stähr P, et al: Transthoracic three-dimensional echocardiographic volumetry of distorted left ventricles using rotational scanning. J Am Soc Echocardiogr 1997; 10:840-852.

18 Sapin PM, Schröder KM, Gopal AS, et al: Comparison of two- and three-dimensional echocardiography with cineventriculography for measurement of left ventricular volume in patients. J Am Coll Cardiol 1994;24:10541063.

19 Buck T, Erbel R: Diagnosis of coronary heart disease by echocardiographic 3D-reconstructions. Global and regional analysis of left ventricular function. Herz 1995;20:252-262.

20 Siu S, Rivera M, Handschumacher MD, et al: Three-dimensional echocardiography: The influence of number of component images on accuracy of left ventricular quantitation. J Am Soc Echocardiogr 1996;9:147-155.

21 Nosir Y, Fioretti PM, Vletter WB, et al: Accurate measurement of left ventricular ejection fraction by three-dimensional echocardiography: A comparison with radionuclide angiography. Circulation 1996;94:460-466.

22 Nosir YF, Salustri A, Kasprzek JD, et al: Left ventricular ejection fraction in patients with normal and distorted left ventricular shape by three-dimensional echocardiographic methods: A comparison with radionuclide angiography. J Am Soc Echocardiogr 1998;11:620630.

23 Rusk RA, Mori Y, Davies CH, et al: Comparison of ventricular volume and mass measurements from B- and C-scan images with the use of real-time 3-dimensional echocardiography: Studies in an in vitro model. J Am Soc Echocardiogr 2000;13:10-17.

24 Schindera ST, Mewald PS, Sahn DJ, Kececioglu D: Accuracy of real-time three-dimensional echocardiography for quantifying right ventricular volume. J Ultrasound Med 2002;21: 1069-1075. 